\title{
First International Conference on Emergency Medicine
}

\author{
Kensington and Chelsea Town Hall, London, England, 14-18 April 1986
}

\section{PROGRAMME}

\section{Monday 14 April 1986}

12.00 onwards Registration in the Town Hall Foyer 14.00-18.00 Annual General Meeting of Casualty Surgeons Association

19.30-22.00 Opening Reception in the Great Hall

Tuesday 15 April 1986

09.00-09.15 Opening Ceremony in the Great Hall

Conference Chairman : William Rutherford

ACEM President : Tom Hamilton

ACEP President : Richard L. Stennes

CAEP President : Sheldon Glazer

CSA President : David H. Wilson

09.15 Theme of the day 'Development and Aspirations of Emergency Medicine' Chairman Tom Hamilton (President, ACEM)

09.20 Development and Aspirations in the United Kingdom David H. Wilson (President, CSA)

09.40 Development and Aspirations in the United States of America Richard L. Stennes (President, ACEP)

10.00 Development and Aspirations in Canada David M. C. Walker (Canada)

10.20 Development and Aspirations in Australia A. D'Arcy (Australia)

10.40 Chairman's closing remarks

10.45 Coffee, exhibition Workshops

11.15 Discussion on papers given in first session 
12.00 Discussion on any two related themes such as:

Selection and training of medical staff, medical audit

Follow up clinics. Computing in emergency care

Care of the young

Care of the adolescent

Care of the elderly

Role of the emergency doctor in accident prevention and

health education

12.45 Lunch, Exhibition

14.00 Free Papers

Room A. Topic/Head injuries

Chairman Brooks F. Bock (USA)

14.00 A comprehensive review of every head-injured patient seen in two accident and emergency departments over a 12-month period

D. W. Yates (Salford, UK)

14.30 Which head-injured patients have a skull fracture?

Marie Brookes (Airdrie, UK)

15.00 The initial management of sub-arachnoid haemorrhage

M. V. Planta (Switzerland)

15.20 Concussion: recovery during and after litigation

Charles Fee (Belfast, UK)

15.40 Psychological sequelae of minor head injury

E. Glucksman (London, UK)

Room B. Topic/Organisation

Chairman N. G. Kirky (UK)

14.00 Development of a system to receive and manage critically-injured patients: a

Saudi Arabian experience

D. S. Wijetung (Saudi Arabia)

14.20 Development of accident and emergency services in the UK: 1880-1985

K. S. Cliff (Winchester, UK)

14.40 Survey of emergency department patient follow-up systems in the United States of America.

G. C. Hamilton (Dayton, Ohio, USA)

15.00 Emergency medicine: the history of the speciality in the United States

Harris B. Graves (Lincon, Nebraska, USA)

15.20 Medical staffing of accident and emergency departments in Australia G. F. Fitzgerald (Ipswich, Australia)

15.40 Assessing the impact of a statewide system of emergency medical services Baladevi S. Shankar (Baltimore, USA)

Room C. Topic/Medical emergencies

Chairman Robert Anthony (Canada)

14.00 Serum catecholamines in cardiac arrest

Mervin A. Wayne (Bellingham, Washington, USA)

14.20 Plant poisons

C. F. Baggoley (Adelaide, Australia)

14.40 Active rewarming as the treatment of choice in hypothermia in the elderly P. E. Randall (Salford, UK) 
15.00 Dangerous marine stings
I. Audley (Cairns, Australia)

15.20 Clinical and biochemical disturbances in the acute phase of carbon monoxide poisoning in man.

Colin E. Robertson (Edinburgh, UK)

15.40 Organisation and implementation of a multidisciplinary team approach for the management of poisoned patients

Kusum Saxena (Little Canada, Minnesota, USA)

Room D. Topic/Pre-hospital care

Chairman Noel Stevenson (Australia)

14.00 Medical control of pre-hospital care in theory and practice

M. Haim Erder (Philadelphia, USA)

14.17 Pre-hospital care: the French organisation

C. Hervé (Creteil, France)

14.34 The pre-hospital emergency Physician service in West Germany

T. Fleischmann-Sperber (Nuremberg, Germany)

14.51 The paramedic in the United Kingdom

F. Robin Glover (Peterborough, UK)

15.08 Gold Coast Hospital Roadside Care and Rescue System

Philip Kay, (Southport, Australia)

15.25 Helicopter transport of trauma patients to a regional trauma unit P. L. Lane (Toronto, Canada)

15.42 Medical care at the US Grand Prix : EMS in microcosm

Raymond E. Fackson (Royal Oak, Michigan, USA)

Room E. Topic/Miscellaneous

Chairman foseph McKean fr (USA)

14.00 Emergency identification and information, a problem in emergency care George Podgorny (Winston-Salem, USA)

14.17 Alcohol levels in accident and emergency medicine P. K. Plunkett (Stockport, UK)

14.34 Alcohol and the National Health Service fohn Gosnold (Hull, UK)

14.51 Deliberate self harm presenting to the accident and emergency department Tom Hamilton (Medlands, WA, Australia)

15.08 Entonox as a supplemental analgesic for the drainage of soft-tissue abcesses Charles B. Payne (UK)

15.25 Sexual assault and child abuse: a change in attitude

Harold A. Fayne (Chicago, Illinois, USA)

15.42 Suicide on the London Underground system $R$. A. Cocks (London, UK)

16.00 Tea, exhibition

16.30 The Maurice Ellis Lecture

Chairman David H. Wilson (President, CSA)

Lecturer William H. Rutherford

Subject The responsibility of Emergency Medicine towards the prevention of road accidents 
Wednesday 16 April 1986

Theme of the day/'Pre-hospital care'

Chairman Sheldon Glazer (President, CAEP)

09.00 Chairman's opening remarks

09.05 Working with Paramedics in the United States of America fohn C. Fohnson (USA)

09.30 Flying squads, cardiac ambulances etc. in Canada

Les Vertesi (Canada)

09.55 Flying doctor in Australia

Noel Stevenson (Australia)

10.20 The UK ambulance service, and its relationship to accident and emergency departments

Keith Little (Edinburgh, UK)

10.45 Coffee, exhibition

\section{Workshops}

11.15 Discussion of theme of the day

12.00 Discussion of related themes such as:

Role of the paramedic

Training of ambulance personnel

Role of the doctor at the site of an accident

Onsite infusions

Onsite treatment of sports injuries

Onsite treatment of industrial injuries

In-flight treatment of air passengers

Medical provision at crowd events

12.45 Lunch, exhibition

14.00-1700 Visit to Wellcome Museum

Thursday 17 April 1986

Theme of the day/ 'Management of trauma'

Chairman David H. Wilson (President, CSA)

09.00 Chairman's opening remarks

09.05 The management of trauma: the role of the emergency physician Peter Lane (Canada)

09.30 Alcohol and trauma

Tom Hamilton (Australia)

09.55 Road accidents and trauma

David Yates and Sheila Christian (UK)

10.20 Aggressive trauma: firearms etc.

George Podgornoy (USA)

10.45 Coffee, exhibition 


\section{Workshops}

11.15 Discussion of theme of the day

12.00 Discussion of related themes such as:

Management of head injuries

Management of chest trauma

Organising a hand injury service

Role of the emergency physician in education and accident prevention

12.45 Lunch, exhibition

\section{Free papers}

Room A. Topic/Trauma

Chairman Eugene Dagnone (Canada)

14.00 Cut extensor tendons of the hand and wrist: is there a 'no man's land'?

W. F. Morgan (Newport, UK)

14.22 Cardiac contusion in people wearing seat-belts

C. L. Muwanga (Middlesborough, UK)

14.45 Brachial plexus injury from blunt trauma: a harbinger of vascular and thoracic injury

Fames T. Sturm (St. Paul, Minnesota, USA)

15.18 Simple out-patient management of lower-limb skin loss in the accident and emergency department with meshed skin grafts and immediate mobilization S. Shankar (Slough, UK)

Room B. Topic/Organisation

Chairman Mr Gautam Bodiwala (UK)

14.00 Microcomputer applications in emergency medicine

P. Cumpston (Canberra, Australia)

14.18 The cost effectiveness of using microcomputers in emergency medicine administration.

Robert L. Prosser (Indianapolis, USA)

14.36 CRISIS: computer-run interactive serious accident simulation Roger Snook (Bath, UK)

14.54 Intergroup conflict and the emergency department

Sapal Tachakra (London, UK)

15.12 Hostage release: immediate care problems

Ian Palmar (Oman)

Room C. Topic/Cardiopulmonary resuscitation

Chairman David S. Nelson (USA)

14.00 Comparison of two therapeutic regimens for bicarbonate therapy in paediatric cardiopulmonary resuscitation

Grace Caputo (Philadelphia, USA)

14.18 Arterial and venous pressure changes during cardiopulmonary resuscitation A. D. Redmond (Stockport, UK)

14.36 Slow versus rapid closed-chest cardiac compression in a paediatric animal model for cardiopulmonary resuscitation

Gary Fleisher (Philadelphia, USA)

14.45 Prognostic factors in patients with out-of-hospital cardiac arrest

Luc Corne (Laarbecklaan, Belgium) 
15.12 Cardiopulmonary bypass in the treatment of prolonged cardiopulmonary㑊 arrest

Gerard B. Martin (Detroit, USA)

Room D. Topic/Pre-hospital care

Chairman foe Epstein (Australia)

14.00 Preliminary experience with pre-hospital defibrillation by protocol

D. R. Williams (Toronto, Canada)

14.18 Effect of MAST on pre-hospital cardiac arrest in an EMS system limited to Basic Life Support.

Richard C. Hunt (Dayton, USA)

14.36 Response and treatment time intervals in an emergency medical services. system.

A. M. Friedberg (Toronto, Canada)

14.54 Specific occupational satisfactions and stresses which differentiate paid and volunteer EMTs

Theodore W. Whitley (Greenville, USA)

15.12 Casualties on Everest: an evacuation problem

R. N. Villar (Acton, UK)

Room E. Topic/Medical audit

Chairman fohn van de leuv (USA)

14.00 Audit of resuscitation in the Accident and Emergency Department of the $\stackrel{\widehat{S}}{\mathcal{S}}$ Royal Hallamshire Hospital, Sheffield

Fames Wardrope (Sheffield, UK)

14.20 A survey of 1000 admissions to a short-stay ward Gillian Bryce (Slough, UK)

14.40 An audit of the accident and emergency department: the role of the department in the community

P. Driscoll (London, UK)

14.50 An audit of the accident and emergency department: accuracy of diagnosis $\stackrel{\bar{\circ}}{3}$ and treatment of chest and abdominal pain

$R$. Brown (London, UK)

15.00 An audit of the accident and emergency department: analysis of assaults P. Driscoll (London, UK)

15.10 An audit of the accident and emergency department: errors in radiographic interpretation

C. Vincent (London, UK)

15.20 An audit of the accident and emergency department: analysis of patient opinion of the accident and emergency department

P. Rich (London, UK)

Room F. Topic/Training

Chairman Vera Dallos

14.00 The development and accreditation of emergency medicine residencies in $\mathrm{N}^{-}$ the United States: 1975-85

fudith E. Tintinalli (Detroit, USA)

14.18 Training staff in emergency medicine

Frank Garlick (Brisbane, Australia) 
14.36 Training housestaff in paediatric resuscitation

D. R. Williams (Toronto, Canada)

14.54 A required combined ACLS/ATLS provider course for senior medical students at East Carolina University

Paul R. Mehne (USA)

15.12 A systematic approach to establishing length of training in graduate emergency medicine

Colin C. Rorrie (Dallas, USA)

15.30 Tea, exhibition

16.00 Symposium 1: Children at risk

Chairman Howard Baderman (London, UK)

16.00 Chairman's introduction

16.10 Sexual abuse of children: management in the accident and emergency department

A. Bentovim (London, UK)

16.50 Serious child abuse : the doctor's role

Louis Blom-Cooper (London, UK)

16.00 Symposium 2: Infectious diseases

Chairman Tina M. Blair (Brockton, Massachusetts, USA)

Speakers:

Adrian M. Griffin-'Fear of Infections in pre-hospital care'

Foseph F. Waeckerle- 'Hepatitis B in emergency care'

Larry F. Baraff-'AIDS'

16.00 Symposium 3: Disasters

Chairman Carlos Perez-Avila (Brighton, UK)

16.05 The medical servity index of disasters

Bo Brismar (Huddinge, Sweden)

16.20 Civil disorder: the Tottenham riots

(i) The Whittington Hospital experience Andrew Heaton

16.30 (ii) The North-Middlesex Hospital experience G. Tiberian

16.40 Massive fire: the Bradford City football ground fire F. B. Hamilton

17.00 Air crash: the Manchester air disaster

F. D. Evans

17.10 Massive motorway traffic accidents

(i) The Preston M6 crash M. Carew McColl

17.20 (ii) The Northampton experience R. G. Daniels

17.30 Terrorist explosion

(i) The Harrod's bomb

Lawrence F. Martin

17.40 (ii) The Brighton bomb

Carlos Perez-Avila 


\section{Friday 18 April 1986}

Theme of the day/ 'Cardiopulmonary resuscitation'

Chairman Richard L. Stennes (President, ACEP)

09.00 Chairman's opening remarks

09.05 Teaching cardiopulmonary resuscitation in the USA Mary Ann Cooper (USA)

09.30 Management of drug-induced arrhythmias Robert Anthony (Canada)

09.56 Management of near drowning in Australia Gary Philips (Australia)

10.20 Cardiopulmonary resuscitation in the United Kingdom: an overview Andrew Marsden (UK)

10.32 A multicare study of cardiopulmonary resuscitation in British hospitals

$$
\text { Linda Bailey (UK) }
$$

10.45 Coffee, exhibition

\section{Workshops}

11.15 Discussion on theme of the day

12.00 Discussion on related topics:

Spontaneous pneumothorax

Inhaled foreign bodies

Toxic inhalation

Cardiac tamponade

Acute heat block

Anaphylactic reaction

12.45 Lunch, exhibition

Room A. Topic/Trauma

Chairman Professor Bo Brismar (Huddinge, Sweden)

14.00 A comparison of the ability of six severity-of-illness scales to predict patient disposition and health-care expenditure in trauma patients

David E. Wilcox (Worcester, USA)

14.20 A technique for reduction of dislocated shoulder using local anaesthetic Brian Walpole (Hobart, Australia)

14.36 The aetiology, management and late sequelea of closed renal trauma Sheila Christian (Slough, UK)

14.54 The ambulatory management of burns Richard A. Cockington (Adelaide, Australia)

15.12 A review of the first 12 months of a hand clinic Neil R. McLean (London, UK)

Room B. Topic/Organisation Chairman Dr Anne D'Arcy (Australia)

14.00 Urgency distribution of an accident and emergency department G. F. Fitzgerald (Ipswich, Australia)

14.18 Experience with a call-receiving algorithm A. M. Friedberg (Toronto, Canada)

14.36 The shift in location of a hospital-based helicopter programme (HEMS) to university hospitals

Fames McKenzie (Ann Arbor, Michigan, USA) 
14.54 Making health care more caring

Gordian Fulde (Darlinghurst, Australia)

15.12 Emergency Medicine 1914-18

Fonathon Marrow (Wirrel, UK)

Room C. Topic/Medical emergencies

Chairman Maureen Turtle (UK)

14.00 Epiglottitis at the extremes of age

Fonathan I. Singer (Dayton, USA)

14.18 Emergency department treatment of migraine with intramuscular chlorpromazine

F. I. McEwen (Canada)

14.36 Acute airflow obstruction in patients presenting to the emergency department: clinical findings and serum theophylline levels

L. F. Dziukas (Preston, Australia)

14.54 Rapid test-strip method for estimating serum CK-MB

Amin H. Nanji (Ottowa, Canada)

15.12 Test strip method for serum theophylline

Amin H. Nanji (Ottowa, Canada)

Room D. Topic/Cardiopulmonary resuscitation

Chairman Dr Fan Ahuja (Canada)

14.00 Combined application of Trendelenberg and PASG in haemorrhagic hypoperfusion

H. Lynn Mayo (Greenville, North Carolina, USA)

14.18 Prehospital myocardial protection during infarction

C. Hervé (France)

14.36 Bystander cardiopulmonary resuscitation: a critical analysis of factors affecting survival

Harlan A. Stueven (Milwaukee, USA)

14.54 Experimental studies with a new airway in cardiopulmonary resuscitation

M. Frass (Vienna, Austria)

15.12 Ventilation performance during cardiopulmonary resuscitation

Fohn B. McCabe (Dayton, USA)

Room E. Topic/Techniques

Chairman Dr Ray Daniels (UK)

14.00 The use of sterile gloves in the management of sutured hand lacerations in the accident and emergency department

A. K. Maitra (Newcastle-upon-Tyne, UK)

14.18 The use of semipermeable, semiocclusive dressing (Coraderm) in the management of minor wounds

Tanya Malpass (London, UK)

14.36 Wound dressings for traumatic wounds

F. David Small (Greenville, North Carolina, USA)

14.54 Catheter perforation of the superior vena cava

A. Bersten (Flinders, Australia)

15.12 Interosseous tibial infusion

A. D. Redmond (Stockport, UK)

Room F. Topic/Miscellaneous

Chairman fohn G. Weigenstein (USA) 
40 First International Conference on Emergency Medicine

14.00 Introduction of cardiopulmonary resuscitation-basic life-support-in primary school

K. Mashiko (Tokyo, Japan)

14.18 No haematuria, no intravenous urogram

Peter Freeland (Belfast, UK)

14.36 A longitudinal study of emergency medicine residents in the first training programme in North America

Rebecca A. H. Anwar (Philadelphia, USA)

14.54 Methodological reporting : comparison of weighted and unweighted analysis Gabor Kelen (Baltimore, USA)

15.12 Medical ethics in the emergency department

Peter D. Bamford (Dunedin, New Zealand)

15.30 Tea, exhibition

Summing up

Chairman William H. Rutherford

16.00 Report by Chairman of Workshop No. 1

16.10 Report by Chairman of Workshop No. 2

16.20 Report by Chairman of Workshop No. 3

16.30 Report by Chairman of Workshop No. 4

16.40 Report by Chairman of Workshop No. 5

16.50 Report by Chairman of Workshop No. 6

17.00 Summing up by conference chairman 